\title{
Identification and antimicrobial susceptibilities of 21 strains of Salmonella from poultry
}

\author{
Yanhong Wang ${ }^{1 *}$, Huijun Shao ${ }^{1 *}$, hualu Sun ${ }^{1}$, Bai Wu${ }^{1}$, Jie Zhu ${ }^{1}$, Wei Hang ${ }^{1}$, Yan Liu ${ }^{1}$ and Feng \\ $\mathrm{Xue}^{2}$
}
${ }^{1}$ Key Laboratory of Animal Infectious Diseases of Ministry of Agriculture, College of Veterinary Medicine, Yangzhou University, Yangzhou, Jiangsu 225009, China.
${ }^{2}$ Animal, Plant \& Food Inspection Center, Jiangsu Entry-exit Inspection and Quarantine Bureau of P.R.C., Nanjing 210001, China.

Accepted 22 May, 2013

\begin{abstract}
A total of 21 Salmonella strains were isolated from clinical cases in Yangzhou, China, and the surrounding areas from Feb 2011 to Dec 2011. All isolates were screened by PCR amplification for InvA gene, which is specific to the Salmonella genus. Thus, twenty-one Salmonella were identified from the specimens. The isolates belonged to 6 serovars of Salmonella. Both Salmonella typhimurium and Salmonella pullorum were the dominant serovars isolated. Results of susceptibility test show that a large percentage of Salmonella were resistant to doxycycline $(90.5 \%)$, polymyxin B $(85.7 \%)$, streptomycin $(85.7 \%)$, lomefloxacin $(85.7 \%)$, and nalidixic acid $(81.0 \%)$. The high resistance among these strains from infection animals suggested that essential measure such as infection control and drug rational use need to be taken.
\end{abstract}

Key words: Salmonella, isolation, identification, serovar, resistance.

\section{INTRODUCTION}

Salmonella is a heterogeneous species of Gram-negative enterobacteria and is a commensal of the intestine of many animal species. Salmonella a pathogen of significant importance in poultry, can cause septicemia and enteritis. Salmonella includes more than 2500 different serotypes (Dunkley et al., 2009; Foley and Lynne, 2008; Popoff et al., 2001). Salmonella pullorum and Salmonella typhimurium are the most prevalent serovars in the worldwide domestic birds (chichen, duck, geese), and may cause significant disease or death in poultry (Pan et al., 2010; Tizard, 2004). Contaminated poultry products are important sources of human Salmonella infections. Moreover, S. typhimurium is the most frequently reported serovars associated with human food-borne illnesses
(Fearnley et al., 2011). Serovars S. typhimurium is most prevalent in geese and ducks. Occurrence of the same Salmonella serovars in humans, animals and food might indicate their epidemiological links (Hoszowski et al., 2012; He et al., 2011; Pan et al., 2010).

Antibiotic-resistant Salmonella are becoming increasingly of concern due to indiscriminate use of antibiotics in animal feeds as growth promoters and therapeutic agents, is a further threat to human and animal health (Forshell and Wierup, 2006). Therefore, resistant strains make it more difficult to treat patients with severe infections. For instance, S. typhimurium DT104 is a high rate of resistance to particular antimicrobials among veterinary isolates in Europe, North America, and Asia (Chiu et 
al., 2006; Futagawa-Saito et al., 2008; Gebreyes et al., 2004; Graziani et al., 2008; Hur et al., 2011; USDA, 2006). The present study was carried out to determine the prevalence of Salmonella serovars in bird infections including chickens, ducks, and geese. All isolates were also examined for antibiotic resistance.

\section{MATERIALS AND METHODS}

Bacterial strains of isolation and culture conditions.

Individual clinical specimens, including liver, ovaries and other organs, were collected from 45 cases of poultry affected by Salmonellosis in Yangzhou and the surrounding areas from February 2011 to December 2011. Most of the animal sampled showed typical clinical signs including septicemia and enteritis. The strains were isolated from the sample, and grown on blood agar (LB containing $5 \%[\mathrm{v} / \mathrm{v}]$ defibrinated sheep's blood) at $35^{\circ} \mathrm{C}$ for $24 \mathrm{~h}$. The subcultures bacteria were streaked onto Luria-Bertani (LB) agar (Oxoid) and MacConkey agar (Shanghai China Academy Of Sciences Shanghai Hexapod Technology Development Co., Ltd.) and incubated at $37^{\circ} \mathrm{C}$ for $24 \mathrm{~h}$.

\section{Amplification of InvA gene}

The InvA gene of the isolated strains was used for Salmonella PCR detection, and amplified enzymatically with the forward primer5'GTGAAATTATCGCCACGTTCGGGCAA3' and reverse primer 5'TCATCGCACCGTCAAAGGAACC-3' according to Rahn (1992) and Malorny (2003). A negative control tube with Escherichia coli S11701 identified and a positive control tube with Salmonella S6702 confirmed by Key Laboratory of Animal Infectious Diseases of Ministry of Agriculture, Yangzhou University, China, DNA were included on each occasion. PCR was performed with the initial denaturation of $3 \mathrm{~min}$ at $95^{\circ} \mathrm{C}$, followed by 30 cycles of denaturation at $94^{\circ} \mathrm{C}$ for $45 \mathrm{sec}$, annealing at $58^{\circ} \mathrm{C}$ for $45 \mathrm{sec}$, extension at $72^{\circ} \mathrm{C}$ for $1 \mathrm{~min}$ and final extension at $72^{\circ} \mathrm{C}$ for $8 \mathrm{~min}$. The expected size of amplicon was approximately $284 \mathrm{bp}$, and visualized by agarose gel electrophoresis on a $1 \%$ agarose gel.

\section{Biochemical tests and Salmonella serovars}

The ability to ferment glucose, mannitol, lactose, sucrose, adonitol, and maltose in the presence of omithine decarboxylase, lysine decarboxylase, and urease activity, and the ability to produce indole, diacetyl, and hydrogen sulfide were performed in conventional tube media for Enterobacteriaceae (Hangzhou Microbial Reagent Co., Ltd, China) at $35^{\circ} \mathrm{C}$ for $24 \mathrm{~h}$. Salmonella serovars was identified by slide agglutination according to the Kauffmann and white scheme.

\section{Antimicrobial susceptibility tests}

Antimicrobial susceptibility tests were done on pure, 1-day-old cultures of all the Salmonella isolates, using the Kirby-Bauer disk diffusion test and antimicrobial susceptibility slip (Hangzhou Microbial Reagent Co., Ltd, China), according to the Clinical and Laboratory Standards Institute (CLSI, 2006) standards.

Strains were evaluated as susceptible, or resistant, and multidrug resistance (MDR) defined as resistance to four or more antibiotics. The following antimicrobials were tested: amikacin $(30 \mu \mathrm{g})$, kanamycin $(30 \mu \mathrm{g})$, gentamycin $(10 \mu \mathrm{g})$, ceftriaxone sodium $(30 \mu \mathrm{g})$, doxycycline $(30 \mu \mathrm{g})$, streptomycin $(10 \mu \mathrm{g})$, levofloxacin $(5 \mu \mathrm{g})$, norxacin $(10 \mu \mathrm{g})$, furazolidone $(300 \mu \mathrm{g})$, polymyxin B (300 IU), sulfamethoxazolum-trimethoprimum $(23 / 75 \mu \mathrm{g})$, lomefloxacin (10 $\mu \mathrm{g})$, chloramphenicol $(30 \mu \mathrm{g})$, and nalidixic acid $(30 \mu \mathrm{g})$.

\section{RESULTS}

\section{Bacterial strains of isolation and Cultural and physiological features}

Of the samples, $46.7 \%$ (21 of 45 ) of salmonellosis cases tested positive for Salmonella using the culture isolation method. The 21 Salmonella isolates belonged to 6 different serovars (Table 1). The predominant serovars were $S$. typhimurium (9/21), and $S$. pullorum (7/21). Other serovars isolated were Salmonella paratyphi $B(2 / 21)$, Salmonella enteritidis (1/21), Salmonella derby (1/21) and Salmonella typhisuis (1/21). In this study, all Salmonella isolates was able to ferment glucose, mannitol, but could not ferment lactose, sucrose, and adonitol and were positive to omithine decarboxylase, lysine decarboxylase, and negative to urease activity, indole, and V-P. Furthermore, variation in the biochemical characterization among maltose and hydrogen sulfide of 21 isolates was found (Table 1).

\section{Salmonella identification}

All isolates tested positive using the culture method and positive control 284 bp band on electrophoresis (Figure1).

\section{Antibiotic resistance profiles of isolates}

A large percentage of Salmonella were resistant to doxycycline $(90.5 \%)$, polymyxin B $(85.7 \%)$, streptomycin (85.7\%), lomefloxacin (85.7\%), and nalidixic acid (81.0\%). In addition, resistance rates of the field strains to gentamycin, norxacin, furazolidone, levofloxacin, sulfamethoxazolum - trimethoprimum, ceftriaxone, kanamycin, amikacin and chloramphenicol were 52.4, 52.4, 38.1, 33.3, 28.6, 28.6, 23.8, 19.1 and 19.1\%, respectively. All the strains were found to be resistant to two or more of the 14 antibiotics tested (Table 2), most (19/21) of isolates had a MDR. A majority (13/21) were co-resistant to lomefloxacin, nalidixic acid, streptomycin, polymyxin B, and doxycycline. Moreover, S2 was resistant to 13 antibiotics except for furazolidone.

\section{DISCUSSION}

Salmonellosis is an important cause of disease and death in poultry and contaminated poultry products pose a significant health hazard to humans (Tizard, 2004). In this study, 21 Salmonella had been isolated form diseased or 
Table 1. Summary of 21 isolates.

\begin{tabular}{|c|c|c|c|c|c|}
\hline Strain & Collection date & Animal species & Maltose & Hydrogen sulfide & Serovar \\
\hline S1 & $24 / 2 / 2011$ & Chicken & - & - & S. pullorum \\
\hline S2 & 24/2/2011 & Chicken & - & - & S. paratyphi B \\
\hline S3 & $24 / 2 / 2011$ & Chicken & - & - & S. pullorum \\
\hline S4 & $26 / 2 / 2011$ & Chicken & - & - & S. Pullorum \\
\hline S5 & $4 / 3 / 2011$ & Geese & + & + & S. typhimurium \\
\hline S6 & $16 / 3 / 2011$ & Geese & + & + & S. paratyphi B \\
\hline S7 & $26 / 3 / 2011$ & Chicken & - & + & S. pullorum \\
\hline S8 & $26 / 3 / 2011$ & Chicken & - & - & S.typhisuis \\
\hline S9 & $4 / 5 / 2011$ & Duck & + & + & S. dublin \\
\hline S10 & $21 / 8 / 2011$ & Geese & + & + & S. typhimurium \\
\hline$S 11$ & $5 / 9 / 2011$ & Duck & + & + & S. typhimurium \\
\hline S12 & $5 / 9 / 2011$ & Hen & - & - & S. pullorum \\
\hline S13 & $27 / 9 / 2011$ & Chicken & + & + & S. pullorum \\
\hline S14 & $13 / 9 / 2011$ & Chicken & - & - & S. pullorum \\
\hline S15 & $14 / 9 / 2011$ & Geese & + & + & S. typhimurium \\
\hline S16 & 24/9/2011 & Geese & + & + & S. typhimurium \\
\hline S17 & 26/9/2011 & Geese & + & + & S. typhimurium \\
\hline S18 & $11 / 10 / 2011$ & Geese & + & + & S. typhimurium \\
\hline S19 & $11 / 11 / 2011$ & Geese & + & + & S. typhimurium \\
\hline S20 & $21 / 12 / 2011$ & Geese & + & + & S. typhimurium \\
\hline $\mathrm{S} 21$ & $31 / 12 / 2011$ & Geese & + & + & S. enteritidis \\
\hline
\end{tabular}

dead birds. From our results, $S$. typhimurium (8/10) was the most prevalent serovars isolated from infected geese. Pan et al. (2010) examined 505 geese faecal samples which were collected between 2008 and 2009 for Salmonella species in China. They reported that 54 samples (10.7\%) form healthy geese were positive for Salmonella, S. typhimurium (18.5), the predominant serovars. Trawinska et al. (2008) found that the serovars S. typhimurium (44.8\%) were predominant in the isolates of geese in 2001-2005 in Poland. However, few reports are available on the prevalence of Salmonella serovars isolated from infected geese. Our results suggest that $S$. typhimurium is a singnificant source of pathogens in geese. On the other hand, S. pullorum (7/9) was the predominant serovars in chickens which is in agreement with Pan et al. (2010) who reported that S. pullorum (84.9\%) was the predominant Salmonella serovar isolated from chickens in Eastern China. S. pullorum, the causative agent of Pullorum disease is the most prevalent hostadapted pathogen in China (Pan et al., 2009). In this study, Other serovars such as $S$. paratyphi B(2/21), $S$. enteritidis (1/21), $S$. derby (1/21) and $S$. typhisuis (1/21) were also isolated form diseased domestic birds such duck and chicken.

Salmonella isolated from infected animal cases (chickens, ducks, and geese) were resistant to doxycycline (90.5\%), polymyxin B $(85.7 \%)$, streptomycin $(85.7 \%)$, lomefloxacin (85.7\%), nalidixic acid (81.0\%), gentamycin $(52.4 \%)$ and norxacin (52.4\%). However, Pan et al. (2010) observed that Salmonella species isolated from faecal samples of healthy domestic animals (chickens, ducks, geese and pigs) were resistant to nalidixic acid $(48.8 \%)$, and streptomycin (38.3\%). The higher resistance rates of Salmonella strains isolated in this study suggests that the strains might have originated from treatments where antimicrobials have been utilized. A low level of resistance to chloramphenicol and furazolidone was found which may be due to their banned use for some time in domestic animals.

This study demonstrated that $S$. typhimurium is the common serovars in geese and a majority of isolates was resistant to multi-drug. $S$. typhimurium is also the major cause of human salmonellosis via contaminated food, becoming increasingly multi-drug resistance (Torpdahl et al., 2013; Cavallaro et al., 2011; Wójcik et al., 2012). Therefore measures to reduce Salmonella infection and antimicrobial usage are important to animals.

\section{ACKNOWLEDGEMENTS}

This work was financially supported by Project Funded by the Priority Academic Program Development of Jiangsu Higher Education Institutions (PAPD), National Key Tech- 


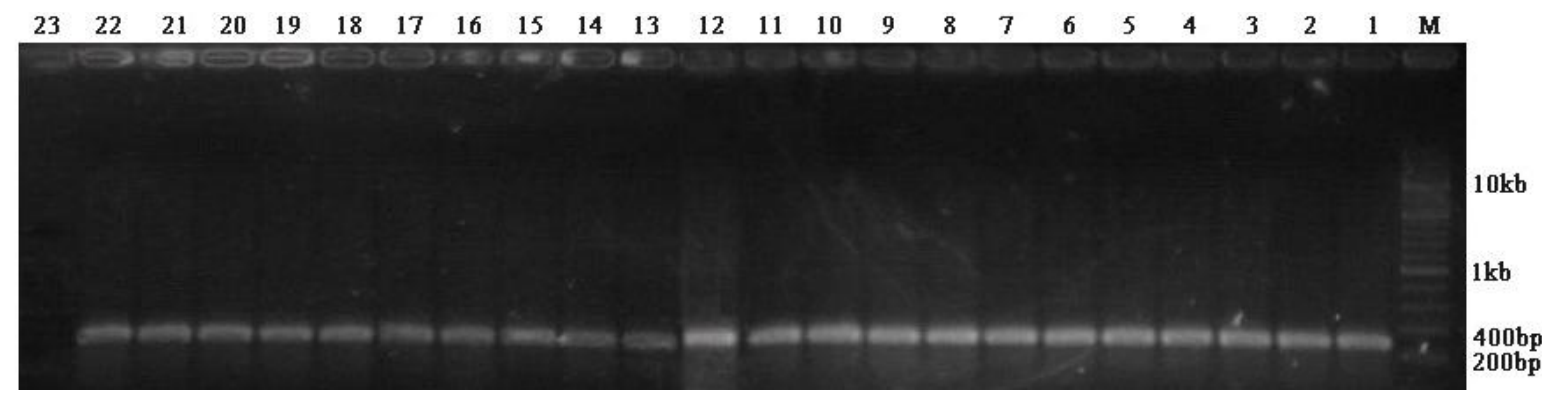

Figure 1. PCR product of invA gene. M, 200bp maker; lane 1-21, 21strains isolated from clinical case; lane 22, positive control; lane 23, negative control.

Table 2. Antimicrobial resistance rates of Salmonella isolates.

\begin{tabular}{lclc}
\hline Antimicrobial & Number (\%) of resistant isolate & Antimicrobial & Number (\%) of resistant isolate \\
\hline Doxycycline & $19(90.5)$ & Furazolidone & $8(38.1)$ \\
Polymyxin B & $18(85.7)$ & Levofloxacin & $7(33.3)$ \\
Streptomycin & $18(85.7)$ & Sulfamethoxazolum-trimethoprimum & $6(28.6)$ \\
Lomefloxacin & $18(85.7)$ & Ceftriaxone & $6(28.6)$ \\
Nalidixic acid & $17(81.0)$ & Kanamycin & $5(23.8)$ \\
Gentamycin & $11(52.4)$ & Amikacin & $4(19.1)$ \\
Norxacin & $11(52.4)$ & Chloramphenicol & $4(19.1)$ \\
\hline
\end{tabular}

nology R \& D Program (2012BAK17B10) and Innovation Fund of Yangzhou University (2011CXJ068), P.R. China.

\section{REFERENCES}

Cavallaro E, Date K, Medus C, Meyer S, Miller B, Kim C, Nowicki S, Cosgrove S, Sweat D, Phan Q, Flint J, Daly ER, Adams J, HyytiaTrees E, Gerner-Smidt P, Hoekstra RM, Schwensohn C, Langer A, Sodha SV, Rogers MC, Angulo FJ, Tauxe RV, Williams IT, Behravesh CB (2011). Salmonella Typhimurium infections associated with peanut products. New. Engl. J. Med. 365: 601-610.

Chiu CH, Su LH, Chu CH, Wang MH, Yeh CM, Weill FX, Chu C (2006). Detection of multidrug-resistant Salmonella enterica serovar Typhimurium phage Type DT102, DT104, and U302 by multiplex PCR. J. Clin. Microbiol. 44: 2354-2358.

Dunkley KD, Callaway TR, Chalova VI, McReynolds JL, Hume ME, Dunkley CS, Kubena LF, Nisbet DJ, Ricke SC (2009). Foodborne Salmonella ecology in the avian gastrointestinal tract. Anaerobe. 15:26-35.

Fearnley E, Raupach J, Lagala F, Cameron S (2011). Salmonella in chicken meat, eggs and humans; Adelaide, South Australia, 2008. Int. J. Food. Microbiol. 146:219-227.

Foley SL and Lynne AM (2008). Food animals-associated Salmonella challenges: Pathogenicity and antimicrobial resistance. J. Anim. Sci. 86: 173-187.

Forshell LP and Wierup M (2006). Salmonella contamination: A significant challenge to the global marketing of animal products. Rev. Sci. Tech. OIE. 25 541-554.

Futagawa-Saito K, Hiratsuka S, Kamibeppu M, Hirosawa T, Oyabu K, Fukuyasu T (2008). Salmonella in healthy pigs: Prevalence, serotype diversity and antimicrobial resistance observed during 1998-1999 and 2004-2005 in Japan. Epidemiol. Infect. 136:1118-1123.

Gebreyes WA, Thakur S, Davies PR, Funk JA, Altier C (2004). Trends in antimicrobial resistance, phage types and integrons among Salmonella serotypes from pigs, 1997-2000. J. Antimicrob.
Chemoth., 53: 997-1003.

Graziani C, Busani L, Dionisi AM, Lucarelli C, Owczarek S, Ricci A, Mancin M, Caprioli A, Luzzi I (2008). Antimicrobial resistance in Salmonella enterica serovar Typhimurium from human and animal sources in Italy. Vet. Microbiol. 128: 414-418.

He GZ, Feng Y, Tian WY, Qian N, Deng SX, An CW (2011). Populations of Salmonella enteritidis in Orally Infected White Chinese Goose. J. Anim. Vet. Adv. 10: 2234-2239.

Hoszowski A, Skarzynska M, Wasyl D, Zajac M, Lalak A, Samcik I, Wnuk D (2012). Salmonella serovars in animals, food and feed during the years 2005-2010 in Poland. Med. Weter., 68(7): 411-417.

Hur J, Choi YY, Park JH, Jeon BW, Lee HS, Kim AR, Lee JH (2011). Antimicrobial resistance, virulence-associated genes, and pulsedfield gel electrophoresis profiles of Salmonella enterica subsp. enterica serovar Typhimurium isolated from piglets with diarrhea in Korea. Can. J. Vet. Res. 75: 49-56.

Malorny B, Hoorfar J, Bunge C, Helmuth R (2003). Multicentre validation of the analytical accuracy of Salmonella PCR: Towards an international standard. Appl. Environ. Microb., 69: 290-296.

Pan ZM, Geng SZ, Zhou YQ, Liu ZY, Fang Q, Liu BB, Jiao XA (2010). Prevalence and antimicrobial resistance of Salmonella sp. isolated from domestic animals in Eastern China. J. Anim. Vet. Adv. 9: 2290-2294.

Pan ZM; Wang XQ, Zhang XM, Geng SZ, Chen X, Pan WJ, Cong QX, Liu XX, Jiao XA, Liu XF (2009). Changes in antimicrobial resistance among Salmonella enterica subspecies enterica serovar Pullorum isolates in China from 1962 to 2007 .Vet. Microbiol. 136 (3-4): 387392.

Popoff MY, Bockemühl J, Gheesling LL (2004). Supplement 2002 (no. 46) to the Kauffmann-White scheme. Res. Microbiol. 155: 568-570.

Rahn K, Grandis SAD, Clarke RC, McEwan SA, Galan JE, Ginocchio C, Curtiss III R, Gyles CL (1992). Amplification of an invA gene sequence of Salmonella Typhimurium by polymerase chain reaction as a specific method of detection of Salmonella. Mol. Cell. Probe., 6: 271-279.

Tizard I (2004). Salmonellosis in Wild Birds. Semin. Avian. Exot. Pet., 13(2): 50-66. 
Torpdahl M, Lauderdale TL, Liang SY, Li I, Wei SH, Chiou CS (2013). Human isolates of Salmonella enterica serovar Typhimurium from Taiwan displayed significantly higher levels of antimicrobial resistance than those from Denmark. Int. J. Food. Microbiol. 161(2): 69-75.

USDA (2006). National antimicrobial resistance monitoring system for enteric bacteria 2004 final report. United States Department of Agriculture. Athens. GA.
Wójcik OP, Kjelsø C, Kuhn KG, Müller L, Jensen T, Kjeldsen MK, Ethelberg $S$ (2012). Salmonella Typhimurium outbreak associated with smoked pork tenderloin in Denmark, January to March 2011. Scand. J. Infect. Dis. 44(12): 903-908. 